\title{
EFFECT OF DIFFERENT CARBON AND NITROGEN SOURCES ON SPORULATION OF BEAUVERIA BASSIANA ROMANIAN STRAINS
}

\author{
Daniel Cojanu*, Cristina-Maria Lumînare \\ Research-Development Institute for Plant Protection Bucharest, Romania \\ * correspondence address \\ Research and Development Institute for Plant Protection Bucharest Ion Ionescu de la Brad 8, 013813, Bucharest, Romania \\ E-mail: cojanu.daniel@icdpp.ro \\ http://www.doi.org/10.54574/RJPP.14.04
}

\begin{abstract}
A requirement for industrial-scale production of mycoinsecticides is the capacity of fungal strains to produce infective and stable propagules on inexpensive artificial substrates, with either solid-state or submerged liquid fermentation methods. The ability of entomopathogenic fungi to use different nutritive substrates is one of the factors influencing their effectiveness. Vegetative growth and sporulation yield depend on the composition of the culture medium and are specific to each fungal isolate. Our study has focused on fungal inoculum produced in artificial media. Native Beauveria bassiana strains was cultivated in liquid medium involving variations in carbon and nitrogen sources and the production of spores was evaluated. The results revealed that among the carbon and nitrogen sources tested, zaharose and ammonium nitrate were most efficiently used for the production of B.bassiana spores in submerged liquid fermentation.
\end{abstract}

Key words: Beauveria bassiana, liquid medium, carbon/nitrogen sources

\section{INTRODUCTION}

Entomopathogenic fungi can provide safe and effective control of many important insect pests. The current interest for the biological plant protection determined the direction of the research towards finding efficient solutions for biotechnological processing of entomopathogenic microorganisms in order to obtain biopesticides. Development of an efficient method for mass production of a mycopesticide requires detailed knowledge of the nutritional requirements for the growth and sporulation of the fungus (Gao, 2011). Biological control using entomopathogenic fungi will only become feasible if economic methods of mass production are available (Jenkins \& Goettel, 1997).

Entomopathogenic fungus Beauveria sp. is considered promising candidate, given its cosmopolitan nature, its potential to control a wide range of harmful insects and its safety to most non-target organisms (Tuan et al., 2009). Other important parameters should be considered for commercial development of mycoinsecticides. For example, the production of infective and stable propagules on inexpensive artificial substrates is a requirement for industrial-scale production with either solid-state or submerged liquid fermentation methods (Jackson et al., 2010). The ability of entomopathogenic fungi to use different nutritive substrates is one of the factors influencing their effectiveness; the conidia germination on insect and in the culture medium is dependent on certain nutritional requirements. The virulence of fungal strains is influenced by the composition of the culture medium used, in vitro cultivation may cause a decrease in virulence, as the growth of fungi on special media ensures a virulence similar to that induced by insect passages (McCoy et al., 1988). On the other hand, the ability of Beauveria bassiana strains to degrade nutrients is a measure of their potential to adapt to varying environmental conditions, an important aspect in the activity of selecting fungal strains to obtain mycoinsecticides. The selection of fungal strains with high potential to adapt to different nutritional substrates guarantees satisfactory yields of fungal biomass both quantitatively and qualitatively. The capacity to use carbon sources is presented as a method to identify and differentiate the fungal isolates of Beauveria and Tolypocladium 
(Todorova et al., 1998), also as a method to phenotypically characterize them (Draganova et al., 2011). The ability of fungal strains to use carbon sources has also been shown to influence their virulence (Pernfus et al., 2003).

Studies on the optimal liquid culture conditions for maximal sporulation of $B$. bassiana have been the subject of numerous papers (Bartlett \& Jaronski, 1988; Brown, 1988; Feng et al., 2000; Pham et al., 2009; Yadav et al., 2013; Andrei, 2004; Dinu, 2013; Fatu, 2016). Bidochka et al. (1990) studied the ability of B. bassiana strains to store carbohydrates in the biomass. Hallswortht and Magan (1994) analized the effect of different carbohydrate concentrations on the growth and accumulation of polyols and trehalose in the conidia of $B$. bassiana, Metarhizium anisopliae, Paratoxotus farinosus. Effect of nitrogen sources on formation of the toxic protease in B. bassiana submerged culture was also studied (Kucera, 1971).

Considering the importance of host-specific isolates for the development of targetspecific mycoinsecticides, the objective of this study was to evaluate the tolerance of some native B.bassiana strains to the different carbon and nitrogen sources, for maximal sporulation in submerged fermentation cultures.

\section{MATERIALS AND METHODS}

Fungal strains $B$. bassiana strains studied in terms of the capacity to use different sources of carbon and nitrogen belong to the Collection of entomopathogenic microorganisms from Research Development Institute for Plant Protection (RDIPP), Bucharest. These are native strains isolated from insects in natural outbreaks of infestation (Figure 1).

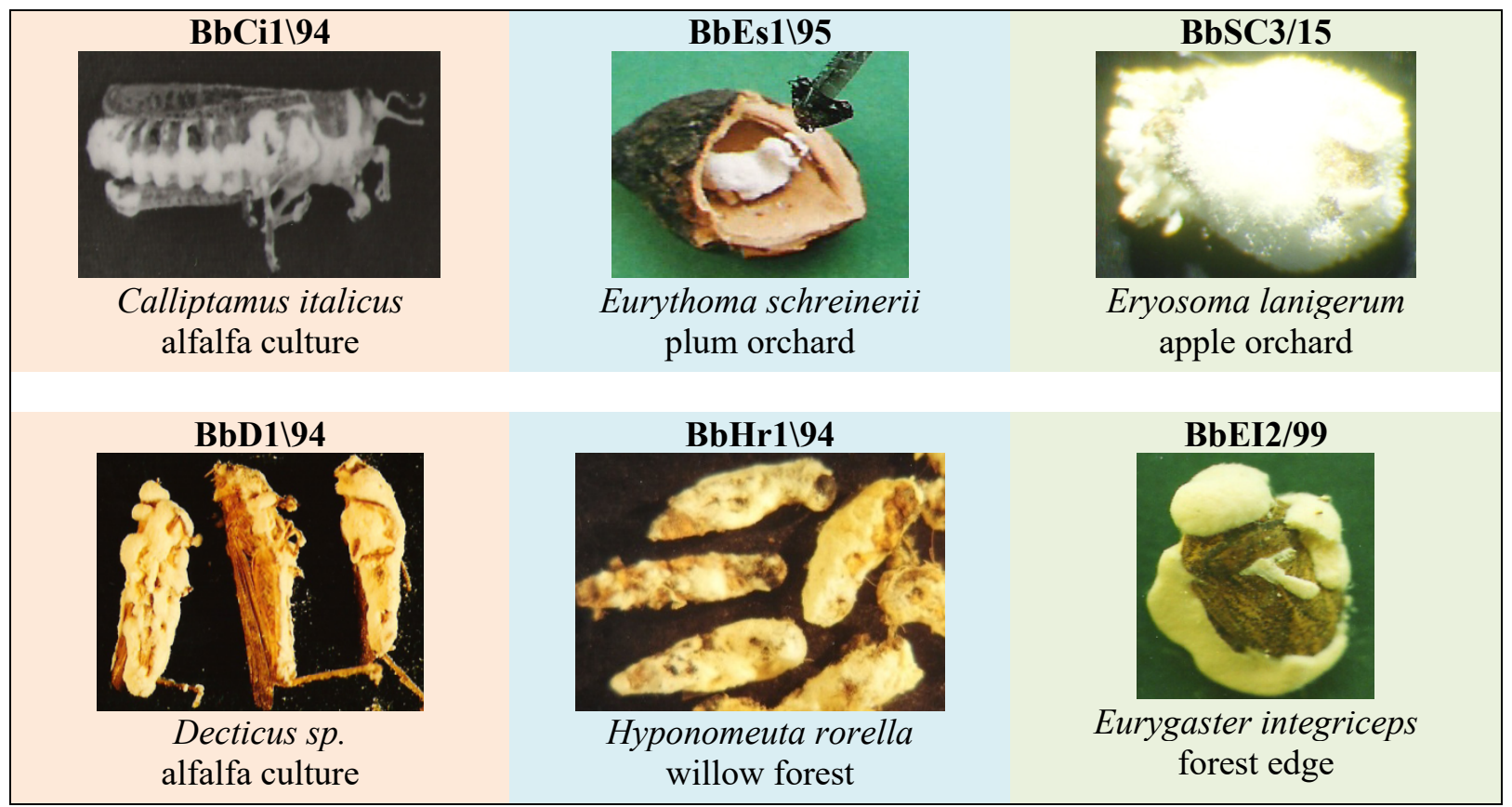

Figure 1. Beauveria bassiana strains studied, abbreviations and sources (host insect/habitat)

Preparation of fungal inoculum The production of the fungal inoculum was done in two stages: (i) laboratory inoculum was obtained by multiplying B. bassiana strains from the stock culture on potato-dextrose-agar medium; (ii) batch inoculum was obtained in submerged culture, using liquid basal medium ( $\mathrm{pH}$ 5.0) based on glucose, $\mathrm{KNO}_{3}, \mathrm{KH}_{2} \mathrm{PO}_{4}, \mathrm{MgSO}_{4}$ and 
trace salts (Thomas et al., 1987), after 5 days incubation period $\left(26^{\circ} \mathrm{C}\right)$. Considering the fact that different fungal isolates vary in their requirements for nutrition, in the basal medium, various carbon sources were incorporated at a final concentration of $6 \mathrm{~g} / \mathrm{l}$. Carbon sources tested were monosaccharides (arabinose, ribose, fructose) disaccharides (zaharose, maltose, lactose) and polisaccharides (celulose, starch); it was also tested molasses (about 40\% zaharose). The nitrogen sources were incorporated in the basal medium at a final concentration of $4 \mathrm{~g} / \mathrm{l}$. Nitrogen sources tested were peptone, yeast extract and some byproducts: wheat bran (by-product of wheat grain milling and grinding), soybean meal (byproduct of the extraction of soybean oil, corn steep liquor (by-product of the corn wet-milling industry).

\section{RESULTS AND DISCUSSION}

The results regarding the capacity of some native B.bassiana strains to use different carbon and nitrogen sources when they are cultivated in liquid medium, are presented graphically in figures 2 and 3.

The average spores yealds had values between 6.13 and $10.28\left(\times 10^{6}\right) / \mathrm{ml}$, with minimum values in the medium containing molasses $\left(4.91 \times 10^{6}\right.$ spores $/ \mathrm{ml}$ - BbEI2/99 strain), cellulose

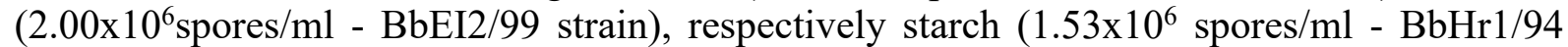
strain). The maximum yealds were registered in the media containing zaharose $\left(13.76 \times 10^{6}\right.$ spores/ml - BbD1/94 strain), respectively fructose (12.89 x106 spores/ml - BbSC strain). Arabinose and ribose were effectively used for sporulation by $\mathrm{BbHr} 1 / 94\left(22.70 \times 10^{6}\right.$ spores $/ \mathrm{ml})$ and BbSC3/15 (12.09 x10 ${ }^{6}$ spores $\left./ \mathrm{ml}\right)$ strains. Similar yealds were recorded in the medium with maltose $\left(12.88 \times 10^{6}\right.$ spores $/ \mathrm{ml}$ - BbD1/94 strain), respectively lactose $\left(11.68 \times 10^{6}\right.$ spores $/ \mathrm{ml}$ - BbSC3/15 strain). Among the nitrogen sources tested, only ammonium nitrate and yeast extract were effectively used in the sporulation process by all strains studied $\left(12.36 \times 10^{6}\right.$ spores $/ \mathrm{ml}$ - BbD1/94 strain, $12.12 \times 10^{6}$ spores $/ \mathrm{ml}-\mathrm{BbSC} 3 / 15$ strain, $22.0 \times 10^{6}$ spores $/ \mathrm{ml}-\mathrm{BbHr} 1 / 94$ strain). In the case of the other nitrogen sources tested, although small amounts of spores were recorded, as in the case of carbon sources, the $\mathrm{BbHr} 1 / 94, \mathrm{BbD} 1 / 94$ and BbSC3/15 strains showed a superior ability to degrade the nutrient substrate. The BbEI2/99 strain proved to have the weakest capacity to use the carbon and nitrogen sources tested; there were maximum yealds of spore in the medium with zaharose $\left(9.01 \times 10^{6}\right.$ spores $\left./ \mathrm{ml}\right)$, followed by fructose $\left(8.20 \times 10^{6}\right.$ spores $\left./ \mathrm{ml}\right)$, lactose $\left(8.02 \times 10^{6}\right.$ spores $/ \mathrm{ml})$. In the case of BbCi1/94 and BbHr1/94 strains, the average yeald was of 1.30 respectively 1.27 lower, compared to BbEI2/99 strain. Zaharose was efficiently used, registering yealds of $13.07 \times 10^{6}$ spores $/ \mathrm{ml}$ (BbHr1/94 strain), respectively $11.34 \times 10^{6}$ spores/ml (BbCi1/94 strain). Among the studied strains, the BbCi1/94 strain used the most efficiently molasses for the production of spores $-13.07 \times 10^{6}$, an amount about 2 times higher than the other strains. The BbSC3/15 strain (average yeald $10.13 \times 10^{6}$ spores $/ \mathrm{ml}$ ) produced large amounts of spores $\left(>12 \times 10^{6}\right)$ in the mediua containing 6 of the carbon sources tested, with highest spores yeald maximum in the medium with zaharose $\left(13.3 \times 10^{6}\right.$ spores $\left./ \mathrm{ml}\right)$, fructose $\left(12.89 \times 10^{6}\right.$ spores $\left./ \mathrm{ml}\right)$, ribose $\left(12.35 \times 10^{6}\right.$ spores $\left./ \mathrm{ml}\right)$, arabinosis $\left(12.09 \times 10^{6}\right.$ spores/ml). 
Arabinose

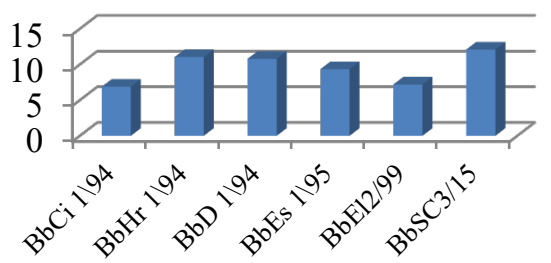

Fructose

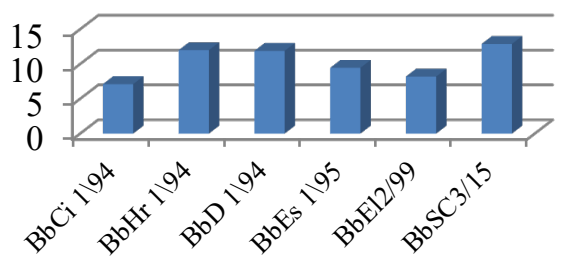

Zaharose

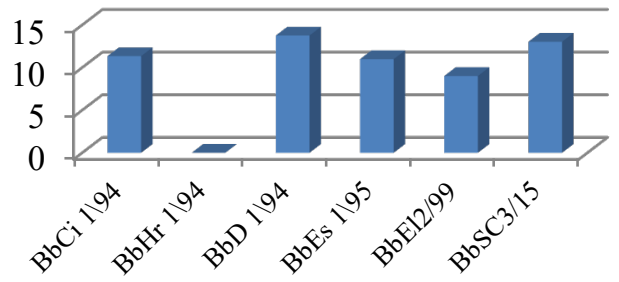

Celulose

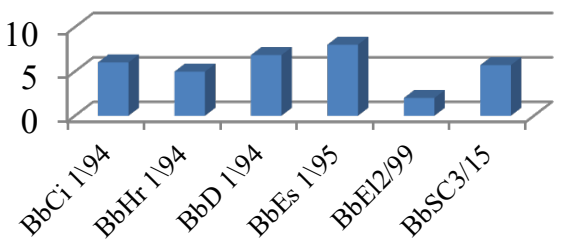

Ribose

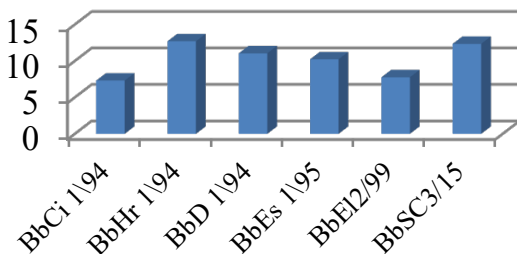

Maltose

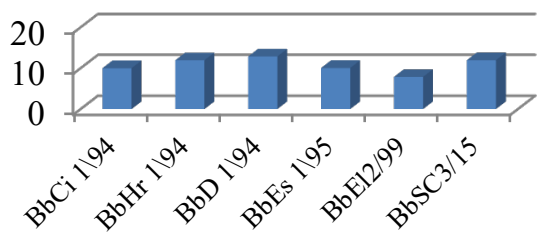

Lactose

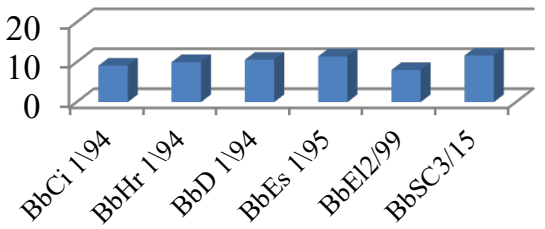

Molasses

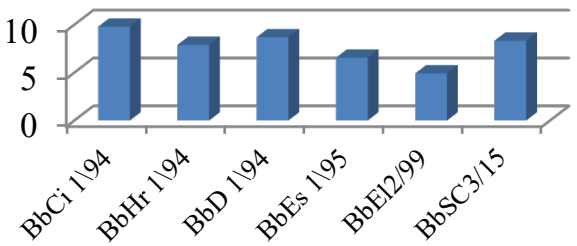

Figure 2. Spore production of $B$. basiana native strains in liquid culture medium containing various carbon sources

The results of our experiment prove that at the same B.bassiana strain, sporulation, expressed by the number of spores $/ \mathrm{ml}$, is different depending on the composition of the culture medium, mainly on the source of carbon and nitrogen. In similar experiments Leite et al. (2003) examined the effects of carbon and nitrogen sources on the growth of three genera of Entomophthorales: Batkoa, Furia, and Neozygites and found that the fungi had similar responses to various carbon sources but different responses to various nitrogen sources. The impact of nutrition on spore yields for various strains of B. bassiana, Paecilomyces fumosoroseus and M. anisopliae was studied by Vega et al. (2003) in six nutritionally different liquid media. The results proved that spore production was variable from one isolate to another. We find the same observation in the studies performed by Kassa et al. (2008); they found that when B. bassiana and M. anisopliae were mass produced on whey, spore yield and viability were significantly influenced by fungal isolate. 


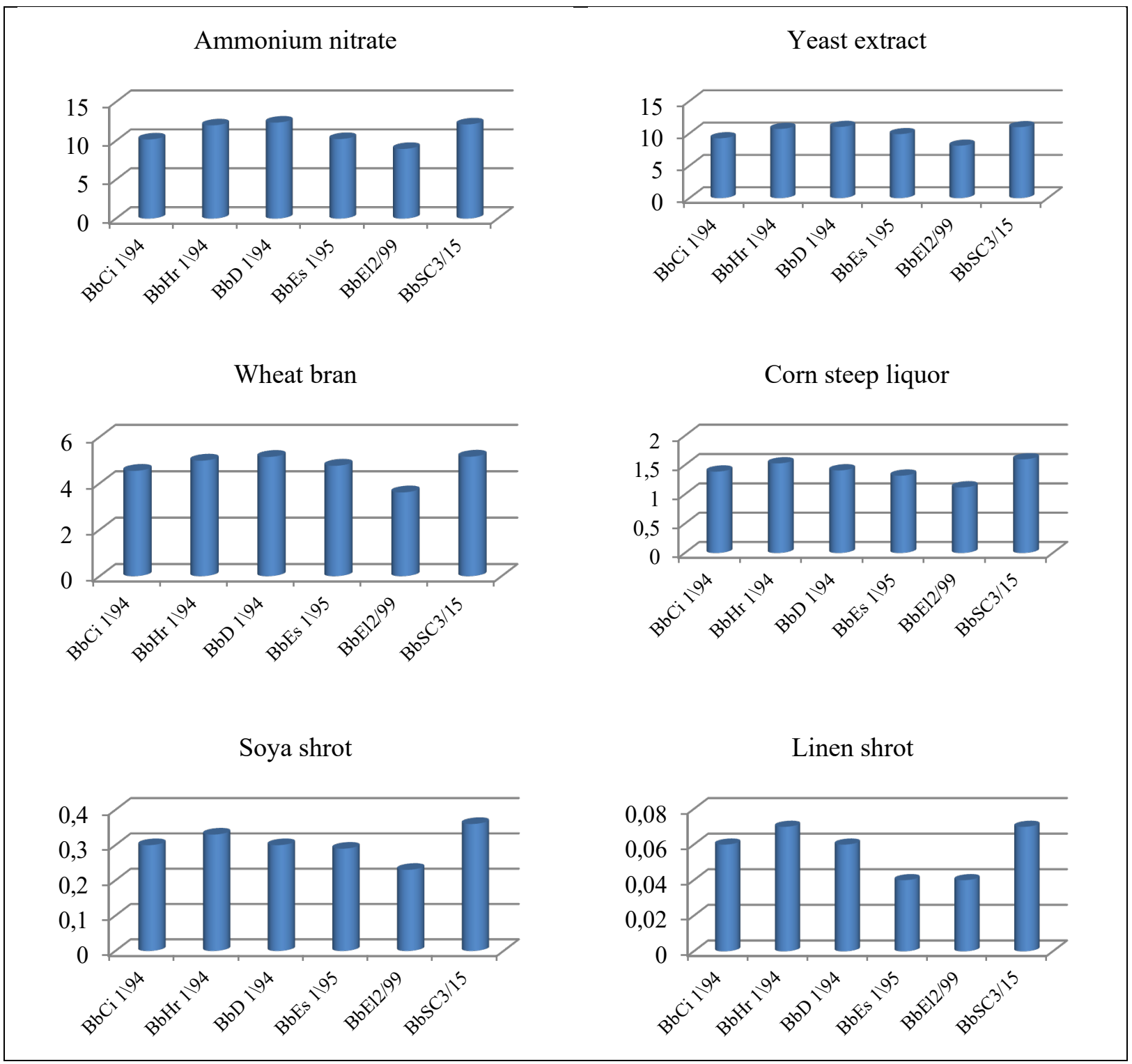

Figure 3. Spore production of $B$. basiana native strains in liquid culture medium containing various nitrogen sources

Barnes et al. (1975) studied the growth and the sporulation of $M$. anisopliae and $B$. bassiana on media containing various peptone sources and they have been reported that $B$. bassiana grew best on melizitose but sporulated best on zaharose, trehalose, and glucose, grew least on rhamnose, sporulated least on sorbose. Bidochka et al. (1987) experimented four liquid media (peptone, peptone-glucose, glucose and glucose-peptone-yeast extract) to define the developmental stages of B.bassiana; they found that in peptone-glucose, the yield of blastospores was four-fold higher than in glucose-peptone-yeast extract and were produced in all liquid media except glucose.

The effect of carbohydrate and nitrogen sources is presented by Rombach et al. (1989) which obtained maximum of $4.62 \times 10^{6}$ conidia/mg dry mycelium produced in a maltose $(2 \%)$ / yeast extract $(0.75 \%)$ medium. Using the data on mycelium yield (in liquid culture) and conidial production (by dry mycelium) it is calculated that the sucrose $(3.5 \%) /$ yeast extract $(3.5 \%)$ and the maltose $(2 \%) /$ yeast extract $(0.75 \%)$ media produce most 
conidia per media volume/an equivalent of 3.52-3.72 $\times 10^{7}$ conidia/ml (Rombach et al., 1988). Hegedus et al. (1990) studied growth, development and sporulation of B. bassiana in microcultures using growth media containing chitin monomers. For the production of submerged conidia growth media containing N-acetyl-D-glucosamine proved to be better than yeast extract-peptone-glucose, glucose plus ammonium salts or $\mathrm{N}$-acetyl-D-galactosamine. In experiments aimed at selecting a medium for maximal sporulation of B. bassiana, these authors reported spore productions of $5.65 \times 10^{7}$ when the carbon source in liquid medium was represented by $3 \%$ sucrose and $1 \%$ casamino acid, after 5 days after inoculation, respectively $8.54 \times 10^{8}$ in medium containing $3 \%$ corn flour, $2 \%$ steep corn powder and $2 \%$ rice bran, after 8 days of inoculation. Thomas et al. (2011) studied the production and properties of $B$. bassiana conidia cultivated in submerged culture and maximum yield of conidia $\left(5 \times 10^{8}\right.$ conidia/mL) was obtained when glucose was the carbon source.

All studies targeting the cultivation of $B$. bassiana focused on the importance of various carbon and nitrogen sources, on submerged spore formation.

\section{CONCLUSIONS}

The results of our experiment prove that at the same B.bassiana strain, sporulation, expressed by the number of spores $/ \mathrm{ml}$, is different depending on the source of carbon and nitrogen. Of the strains tested in this study, the $\mathrm{BbD} 1 / 94$ strain recorded the highest average yeald of spores - $10,28 \times 10^{6}$ in media containing various sources of carbon, respectively $12,36 \times 10^{7}$ media containing various sources of nitrogen.

Cultivation on media containing different carbon and nitrogen sources proves the ability of $B$. bassiana to degrade different nutrient substrates, the yield in active biomass being different from one strain to another. Therefore, the ability of each fungal strain to use different nutrient substrates is a measure of its potential to adapt to highly variable environmental conditions. This is the reason why we recommend that the release of any B.bassiana strain in different habitats to be preceded by testing its ability to use a wide a range of nutrients, mainly carbon and nitrogen sources.

\section{Acknowledgement}

This work was supported by a grant of the Romanian Ministery of Research and Innovation, CCCDIUEFISCDI, project number PN-III-P1-1.2-PCCDI-2017-03-01/28PCCDI/2018, within PNCDI III.

\section{REFERENCES}

ANDREI, A.M. (2004). Technological elements for obtaining Beauveria bassiana biological. Conferința națională pentru protecția mediului prin mijloace biologice și biotehnice/Conferința naționale de ecosanogeneză. Ed. Pelecanus Brasov, 8-13.

BARNES, G.L., BOETHEL, D.J., EIKENBARY, R.D., CRISWELL, J.T., GENTRY, C.R. (1975). Growth and sporulation of Metarrhizium anisopliae and Beauveria bassiana on media containing various peptone sources. Journal of Invertebrate Pathology, 25, 3, 301-305.

BARTLETT, M. C., JARONSKI, S. T. (1988). Mass production of entomogenous fungi for biological control of insects. Ed. M.N Burge, Fungi in Biological Control Systems. Manchester, NY: Manchester University Press, 65-85.

BIDOCHKA, M.J., LEGER, R.J., JOSHI, L., ROBERTS, D.W. (1995). The rodlet layer from aerial and submerged conidia of the entomopathogenic fungus Beauveria bassiana contains hydrophobin. Mycological Research, 99, 403-406.

BIDOCHKA, M.J., LOW, N.H., KHACHATOURIANS G.C. (1990). Carbohydrate storage in the entomopathogenic fungus Beauveria bassiana. Applied and Enviromental Microbiology, 56, 31863190 . 
BIDOCHKA, M.J., PFEIFER, T.A., KHACHATOURIANS, G.G. (1987). Development of the entomopathogenic fungus Beauveria bassiana in liquid cultures. Mycopathologia, 77-83, doi: 10.1007/BF00436909.

BROWN, D.E. (1988). The submerged culture of flamentous fungi. In: Berry DR, editor, Physiology of Industrial Fungi. Blackwell Scientific Publications, 219-248.

DINU, M.M., FÂTU, A.C., ANDREI, A.M. (2013). Microbial fermentation processes used to obtain fungal bioinsecticides. Ed. Alpfa MDN, 58.

DRAGANOVA, S.A., PILARSKA, D.K., TAKOV, D.I., DOYCHEV, D.D. (2011). Utilization of carbohydrates by Beauveria bassiana isolates obtained from forest pests. Journal of Plant Protection Research, 51, 4, 349-354.

FĂTU, A.C., DINU, M.M., ANDREI, A.M. (2016). Improved technology for obtaining fungal bioinsecticides designed to protect agricultural and silvicultural crops. Proceedings of ISB-INMA TEH' Agricultural and mechanical engineering, 245-250.

FENG, K.C., LIU, B.L., TZENG, Y.M. (2000). Verticillium lecanii spore production in solid-state and liquid-state fermentation. Bioprocess Engineering, 23, 25-29.

GAO, L. (2011). A novel method to optimize culture conditions for biomass and sporulation of the entomopathogenic fungus Beauveria Bassiana IBC1201. Brazilian Journal Microbiology, 42, 4, 1574 1584. http://dx.doi.org/10.1590/S1517-83822011000400045.

HALLSWORTHT, J.E., NARESH, M. (1994). Effect of carbohydrate type and concentration on polyhydroxy alcohol and trehalose content of conidia of three entomopathogenic fungi. Microbiology, $140,2705-2713$.

HEGEDUS, D.D., BIDOCHKA, M.J., KHACHATOURIANS, G.G. (1990). Beauveria bassiana submerged conidia production in a defined medium containing chitin, two hexosamines or glucose. Applied and Enviromental Microbiology, 33, 641-647. https://doi.org/10.1007/BF00604930.

HOLDER, D.J., KEYHANI, N.O. (2005). Adhesion of the entomopathogenic fungus Beauveria (Cordyceps) bassiana to substrata. Applied and environmental microbiology, 71, 9, 5260-5266. doi:10.1128/AEM.71.9.5260-5266.2005.

JACKSON, M.A., DUNLAP, C.A., JARONSKI, S. (2010). Ecological considerations in producing and formulating fungal entomopathogens for use in insect biocontrol. Bio Control, 55, 129-145.

JENKINS, N.E., GOETTEL, M.S. (1997). Methods for mass production of microbial control agents of grasshoppers and locusts. Memoirs of the Entomological Society of Canada, 171, 37-48.

KASSA, A., BROWNBRIDGE, M., PARKER, B.L., SKINNER, M., GOULI, S., GUO, M., LEE, F., HATA, T. (2008). Whey for mass production of Beauveria bassiana and Metarhizium anisopliae. Mycological Research, 583-591. doi: 10.1016/j.mycres.2007.12.004.

KUČERA, M. (1971). Toxins of the entomophagous fungus Beauveria bassiana: II Effect of nitrogen sources on formation of the toxic protease in submerged culture. Journal of Invertebrate Pathology, 211-215. doi: 10.1016/0022-2011(71)90093-0.

LEITE, L.G., ALVES, S.B., BATISTA, F.A., ROBERTS, D.W. (2003). Effect of salts, vitamins, sugars and nitrogen sources on the growth of three genera of Entomophthorales: Batkoa, Furia, and Neozygites. Mycological Research, 107, 872-878.

LOESCH, A., STEFAN, H., HERMANN, S. (2010). Carbon utilization pattern as a potential quality control criterion for virulence of Beauveria brongniartii. Journal of Invertebrate Pathology, 104, 5865 .

MCCOY, C.W., SAMSON, R.A., BOUCIAS, D.G. (1988). Entomogenous fungi, in "CRC Handbook of Natural Pesticides. Microbial Insecticides, Entomo genous Protozoa and Fungi", Ed. Ignoffo, 5, 151-236.

PERNFUSS, B., SCHWEIGKOFLER, W., STRASSER, H. (2003). Distinction of the entomopathogenic fungal species Beauveria brongniartii and Beauveria bassiana by comparing their carbon utilization patterns. IOBC wprs Bulletin, 26, 1, 121-123.

PHAM, T.A., KIM, J.J., KIM, S.G., KIM, K. (2009). Production of blastospore of entomopathogenic B. bassiana in a submerged batch culture. Microbiolog, 37(3), 218-24.

ROMBACH, M.C. (1989). Production of Beauveria bassiana [Deuteromycotina: hyphomycetes] sympoduloconidia in submerged culture. Entomophaga, 45-52. doi: 10.1007/BF02372586. 
ROMBACH, M.C., AGUDA, R.M., ROBERTS, D.W. (1988). Production of Beauveria bassiana [Deuteromycotina: Hyphomycetes] in different liquid media and subsequent conidiation of dry mycelium. Entomophaga, 4, 315-324. doi: 10.1007/BF02372621.

STEFAN, T., JACKSON, J.M.A. (2012). Mass production of entomopathogenic Hypocreales. Manual of Techniques. Invertebrate Pathology, 255-284. doi.org/10.1016/B978-0-12-386899-2.00008-7.

THOMAS, K.C., KHACHATOURIANS, G., INGLEDEW, W.M. (2011). Production and properties of Beauveria bassiana conidia cultivated in submerged culture. Canadian Journal of Microbiology, $33,1,12-20$.

TODOROVA, S., CÔTÉ, J.C., CODERRE, D. (1998). Distinction between Beauveria and Tolypocladium by carbohydrate utilization. Mycological Research, 102, 1, 81-87.

VEGA, F.E., JACKSON, M.A., MERCADIER, G., POPRAWSKI, T.J. (2003). The impact of nutrition on spore yields for various fungal entomopathogens in liquid culture. World Journal of Microbiology and Biotechnology, 363-368. doi: 10.1023/A:1023924304456.

YADAV, S., TANDAN, N., KUMAR, K. (2013). Effect of different carbon and nitrogen sources on the biomass of Beauveria bassiana. International Journal of Advanced Biotechnology Research, 3, 3, 374-376. 